\title{
Magnetocaloric Properties of Melt-Spun Fe-Ni-Mn-Ga Ribbons
}

\author{
C. W. Shih ${ }^{1}$, X. G. Zhao ${ }^{2}$, H. W. Chang ${ }^{3}$, Y. C. Tseng ${ }^{4}$, and W. C. Chang ${ }^{1}$ \\ ${ }^{1}$ Department of Physics, National Chung Cheng University, Chia-Yi, 621 Taiwan, ROC \\ ${ }^{2}$ Shenyang National Laboratory for Materials Science, Institute of Metal Research, Chinese Academy of Sciences, Shenyang \\ 110016, China \\ ${ }^{3}$ Department of Applied Physics, Tunghai University, Taichung, Taiwan, ROC \\ ${ }^{4}$ Department of Materials Science and Engineering, National Chiao Tung University, Hsin-chu 30010, Taiwan, ROC
}

\begin{abstract}
The effects of $\mathrm{Ni}$ substitution for $\mathrm{Fe}$ on phase constitutions, Curie temperature $\mathbf{T}_{\mathrm{C}}$, and magnetocaloric properties of melt-spun $\mathrm{Fe}_{50-\mathrm{x}} \mathrm{Ni}_{\mathrm{x}} \mathrm{Mn}_{25} \mathrm{Ga}_{25}(\mathrm{x}=\mathbf{0}, 1,3,5$ and 7) ribbons have been investigated. $\mathrm{X}$-ray diffraction results show that the main phase in the $\mathrm{Fe}_{50-\mathrm{x}} \mathrm{Ni}_{\mathrm{x}} \mathrm{Mn}_{25} \mathrm{Ga}_{25}(\mathrm{x}=0-7)$ alloy changed with the increase of Ni content from FCC structure for $\mathrm{x}=0$ into $\mathrm{B} 2$ structure for $\mathrm{x}=1-7$. Besides, the magnetic phase exhibits phase transition of ferromagnetic into paramagnetic state with increasing temperature for the samples with B2-type structure. The Curie temperature $T_{C}$ of these ribbons varies in the temperature range of 232-257 $\mathrm{K}$. The peak values of the maximal magnetic entropy change, $-\Delta S_{M}{ }^{\text {max }}$, are about 1.4-1.6 Jkg/K for Ni-substituted ribbons at a maximum applied field of $30 \mathrm{kOe}$. On the other hand, the relatively broader temperature range at the half maximum of $\Delta S_{M}$ peak $(\sim 90 \mathrm{~K})$, low-cost and nontoxic elements make $\mathrm{Fe}-\mathrm{Ni}-\mathrm{Mn}-\mathrm{Ga}$-based ribbons the promising candidates for magnetic refrigeration applications close to room temperature.
\end{abstract}

Index Terms-Heusler alloy, magnetocaloric properties, melt-spun ribbon.

\section{INTRODUCTION}

$\mathbf{S}$ INCE a large magnetic field-induced strain (MFIS) associated with a rearrangement of martensite variants by an external magnetic field in $\mathrm{Ni}-\mathrm{Mn}-\mathrm{Ga}$ alloys was first reported in 1996, [1] ferromagnetic shape memory alloys (FSMAs) have attracted significant attention due to their interesting physical properties, such as large magnetic-field-induced strain, [1], [2] giant magnetocaloric effects (MCEs), [3], [4] large magnetoresistance (MR), [5], [6] and exchange bias (EB) behavior [7], [8]. These properties make them a promising candidate as potential material for various practical applications in the field of smart, magnetic refrigeration and spintronics.

In contrast to most developed Ni-Mn based Heusler alloys, another representative of the FSMAs, i.e., Fe-Mn based system, has not received much attention up to now, such as $\mathrm{Fe}-\mathrm{Mn}-\mathrm{Ga}$ alloys, which also possess many of the above-mentioned features. Recently, Zhu et al. have reported that for a slightly off-stoichiometric $\mathrm{Fe}_{50} \mathrm{Mn}_{22.5} \mathrm{Ga}_{27.5}$ alloy, a field-induced transformation from a paramagnetic (PM) parent phase to a ferromagnetic (FM) martensite phase takes place at $163 \mathrm{~K}$ (on cooling), leading to a large lattice distortion of $33.5 \%$; in the meantime, a large shape memory strain up to about $3.6 \%$ is observed due to the martensite transformation (MT) [9]. On the other hand, the giant EB effect was observed in stoichiometric $\mathrm{Fe}_{2} \mathrm{MnGa}$ alloy ribbon, because transformation from antiferromagnetic (AFM) to FM phase can be induced by applying a magnetic field or by changing the temperature.

Manuscript received May 05, 2013; revised July 17, 2013; accepted July 24, 2013. Date of current version December 23, 2013. Corresponding author: W. C. Chang (e-mail:phywcc@ccu.edu.tw).

Color versions of one or more of the figures in this paper are available online at http://ieeexplore.ieee.org.

Digital Object Identifier 10.1109/TMAG.2013.2276091
In addition, the EB behavior and enhanced coercivity occur simultaneously, revealing an exchange coupling between the coexisting antiferromagnetic and ferromagnetic phase [10], [11].

In our previous work, we reported phase transformation and $\mathrm{EB}$ behavior in as-spun $\mathrm{Fe}-\mathrm{Mn}-\mathrm{Ga}$ ribbons [12]. However, to date, there is no report on the effect of other magnetic elements' (Co or Ni) addition on the structure and magnetic phase evolution of $\mathrm{Fe}-\mathrm{Mn}-\mathrm{Ga}$ melt-spun ribbon systems. In this present work, the effect of Ni substitution for Fe on the crystal structure, magnetic state and magnetocaloric effect of the $\mathrm{Fe}-\mathrm{Ni}-\mathrm{Mn}-\mathrm{Ga}$ Heusler alloy ribbons are reported.

\section{EXPERIMENT}

The alloys with the nominal composition of $\mathrm{Fe}_{50-\mathrm{x}} \mathrm{Ni}_{\mathrm{x}} \mathrm{Mn}_{25} \mathrm{Ga}_{25}$ ( $\mathrm{x}=0,1,3,5$ and 7$)$ were prepared using arc melting pure elements $(>99.9 \%)$ in a high-purity argon atmosphere. To compensate for Mn losses during processing, an excess of $6 \mathrm{wt} . \% \mathrm{Mn}$ was added. The ingot was melted three times to ensure homogeneity, and then melt-spun with a single-roll melt-spinner at a wheel linear speed of $15 \mathrm{~m} / \mathrm{s}$. The crystal structure of the ribbons was identified by X-ray diffraction (XRD) using $\mathrm{Cu}-K \alpha$ radiation at room temperature. Magnetic measurements were performed in the temperature interval of $10-330 \mathrm{~K}$, and in external magnetic fields up to $30 \mathrm{kOe}$, using a physical properties measuring system (PPMS, Quantum Design Inc.) platform with a vibrating sample magnetometer module. The magnetic field was applied along the ribbon plane direction. Zero-field-cooled (ZFC) and field-cooled (FC) thermomagnetic curves were recorded at 200 Oe with a temperature heating or cooling rate of $10 \mathrm{~K} / \mathrm{min}$. Magnetic phase transition temperature was inferred from the maximum or minimum in the $d M / d T$ versus $T$ curve. The maximum magnetic entropy changes $\Delta \mathrm{S}_{\mathrm{M}}(\mathrm{T}, \mathrm{H})$ 


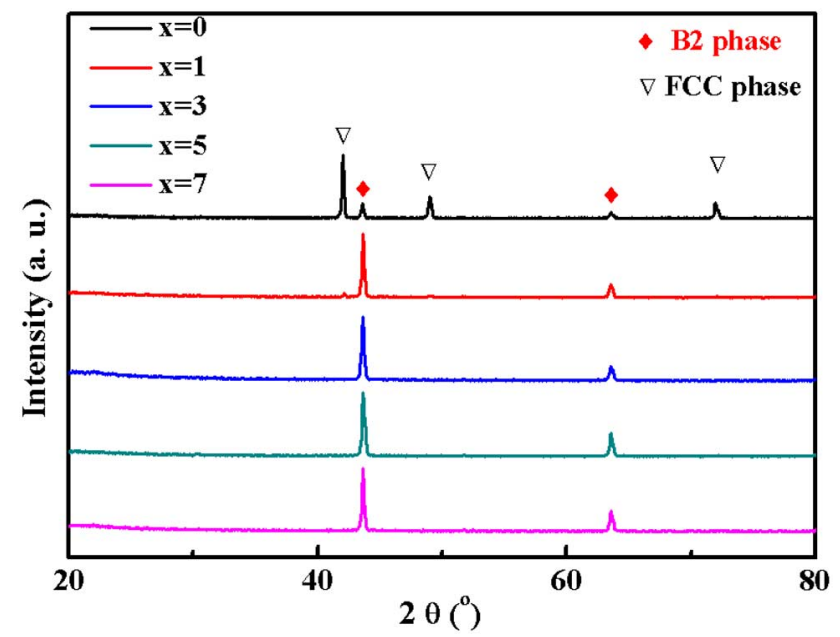

Fig. 1. XRD patterns of the melt spun $\mathrm{Fe}_{50-\mathrm{x}} \mathrm{Ni}_{\mathrm{x}} \mathrm{Mn}_{25} \mathrm{Ga}_{25}(\mathrm{x}=0,1,3,5$ and 7) ribbons at room temperature.

were calculated from isothermal magnetization curves using the Maxwell relation [13]

$$
\Delta S_{M}(T, H)=\int_{0}^{H}\left(\frac{\partial M}{\partial T}\right)_{H} d H
$$

\section{RESULTS AND DISCUSSION}

Fig. 1 shows XRD patterns of the as-spun $\mathrm{Fe}_{50-\mathrm{x}} \mathrm{Ni}_{\mathrm{x}} \mathrm{Mn}_{25} \mathrm{Ga}_{25}(\mathrm{x}=0,1,3,5$ and 7$)$ ribbons at room temperature. The crystal structure of these series ribbons includes two kinds of structures, an ordered face-center-cubic (fcc) lattice of $\mathrm{L} 1_{2}$-type $\left(\mathrm{Cu}_{3} \mathrm{Au}\right)$ for $\mathrm{x}=0$ and a partially ordered $\mathrm{B} 2$ phase for $\mathrm{x}=1-7$, respectively. According to the results of previous reports, stoichiometric $\mathrm{Fe}_{2} \mathrm{MnGa}$ alloy should have the stable $\mathrm{L} 2{ }_{1}$-type of structure [14]. However, it was experimentally found that stoichiometric $\mathrm{Fe}_{2} \mathrm{MnGa}$ alloy crystallizes in a fcc-type structure [9], [10], [15]. Theoretical results reported by Kudryavtsev et al. [16] showed that the L2 ${ }_{1}$-type crystal structure with a lattice constant of $\mathrm{a}=0.57 \mathrm{~nm}$ in $\mathrm{Fe}_{2} \mathrm{MnGa}$ is stable with ferrimagnetic order, instead of FM order. On the other hand, stable ordered fcc-type structure with lattice constants of a $=0.3644 \mathrm{~nm}$ and $\mathrm{a}=0.3666 \mathrm{~nm}$ exhibited ferromagnetic and ferrimagnetic order, respectively. In this work, for $\mathrm{x}=0$ samples, the main phase is found ordered fcc lattice of $\mathrm{L}_{2}$-type $\left(\mathrm{Cu}_{3} \mathrm{Au}\right)$, implying that the structure of ordered fcc-type is more stable than $\mathrm{L}_{1}$-type in $\mathrm{Fe}_{2} \mathrm{MnGa}$ alloy. However, for alloy ribbons with $\mathrm{x}>1$, the main phase of ribbons changes into B2 structure. It is presumed that a chemical disorder B2 phase favors to form due to Ni-added alloy systems consisting of more than three elements [17] and also rapid solidification process.

Fig. 2 shows zero-field cooled (ZFC) and field-cooled (FC) magnetization as a function of temperature $M(T)$ of $\mathrm{Fe}_{50-\mathrm{x}} \mathrm{Ni}_{\mathrm{x}} \mathrm{Mn}_{25} \mathrm{Ga}_{25}$ ribbons with $\mathrm{x}=0$ and 1. It is seen that the behaviors of these two curves are quite different. For $\mathrm{x}=0$, a sudden jump in magnetization with increasing temperature

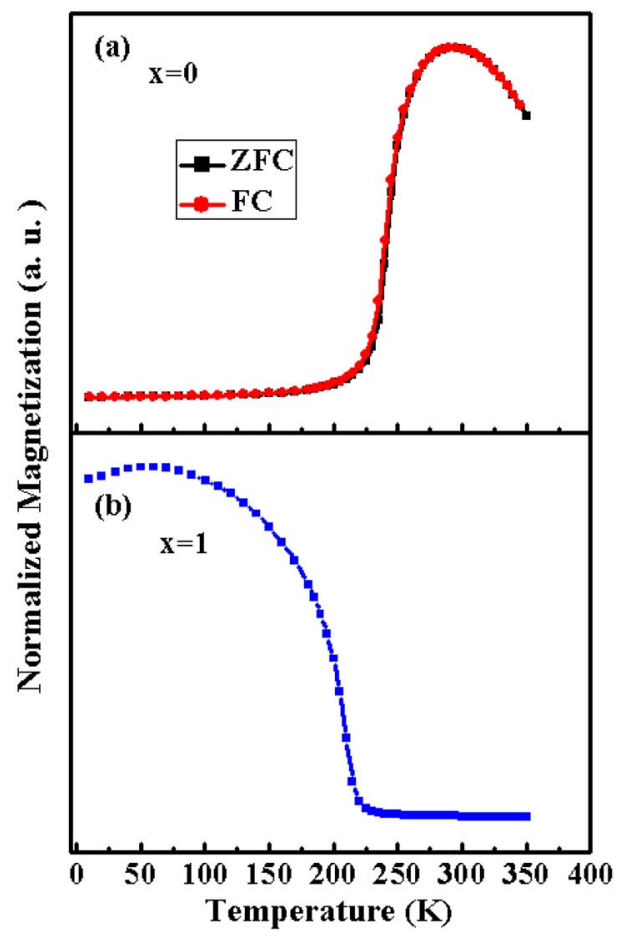

Fig. 2. (a) $\mathrm{ZFC}$ and $\mathrm{FC}$ magnetization curves as a function of temperature of $\mathrm{Fe}_{50} \mathrm{Mn}_{25} \mathrm{Ga}_{25}$ and (b) of $\mathrm{Fe}_{49} \mathrm{Ni}_{1} \mathrm{Mn}_{25} \mathrm{Ga}_{25}$ ribbons obtained at a field of 200 Oe.

is observed. In addition, the magnetization curves recorded in field-cooled and field-warmed procedures are almost overlapped around the magnetic phase transition, indicating the second-order nature of the magnetic transitions. The structure and magnetic phase transition of the ribbons with $\mathrm{x}=0$ are consistent with previous work [12], that is, magnetic phase transition of fec structure from antiferromagnetic (AFM) to FM with increasing temperature. For $\mathrm{Ni}$-added ribbons with $\mathrm{x}=1$, it exhibits a magnetic phase transition at $\mathrm{T}_{\mathrm{C}}=232 \mathrm{~K}$, which corresponds to Curie temperature of B2-type phase change from FM to PM state.

The temperature dependence of magnetization $M(T)$ curves of $\mathrm{Fe}_{50-\mathrm{x}} \mathrm{Ni}_{\mathrm{x}} \mathrm{Mn}_{25} \mathrm{Ga}_{25}(\mathrm{x}=1-7)$ ribbons, measured in an applied field of $1 \mathrm{kOe}$ and temperature range from 190 to $380 \mathrm{~K}$, are shown in Fig. 3(a), and their corresponding dM/dT-versus- $\mathrm{T}$ curves are shown in Fig. 3(b). The Curie temperature $\mathrm{T}_{\mathrm{C}}$ values, obtained from the $\mathrm{M}-\mathrm{T}$ curves, are summarized in Table I. From the results of Fig. 3, it can be found that the $T_{C}$ and magnetization of $\mathrm{B} 2$ phase are increased with increasing Ni concentration. In B2-type structure, the magnetic moments depend mainly on anti-parallel coupling of $\mathrm{Mn}$ atoms and $\mathrm{Fe}$ atoms. Hence, a part of Fe replaced by Ni might reduce the exchange coupling of $\mathrm{Fe}$ and $\mathrm{Mn}$ atoms, leading to the enhancement of magnetization and Curie temperature.

The isothermal magnetization curves for $\mathrm{Fe}_{50-\mathrm{x}} \mathrm{Ni}_{\mathrm{x}} \mathrm{Mn}_{25} \mathrm{Ga}_{25}(\mathrm{x}=1-7)$ ribbons are measured with an increasing magnetic field in a wide temperature range. The MCE as a function of temperature and magnetic field was calculated from the isothermal magnetization curves using the Maxwell relation under 0-30 kOe magnetic field changes. The M-H curves of representative $\mathrm{Fe}_{49} \mathrm{Ni}_{1} \mathrm{Mn}_{25} \mathrm{Ga}_{25}$ ribbons 


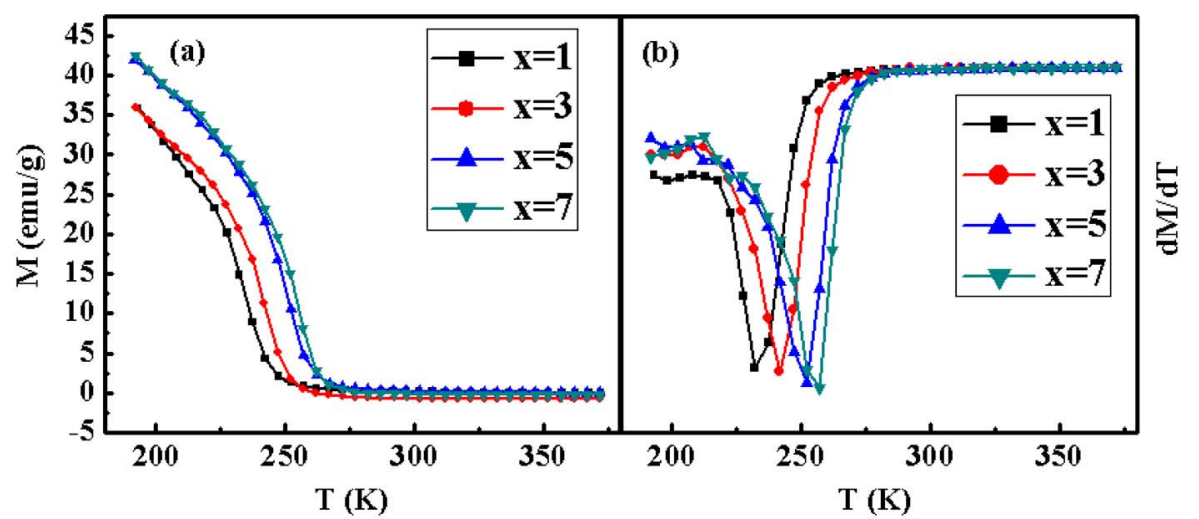

Fig. 3. Magnetization curves as a function of temperature of $\mathrm{Fe}_{50-\mathrm{x}} \mathrm{Ni}_{\mathrm{x}} \mathrm{Mn}_{25} \mathrm{Ga}_{25}(\mathrm{x}=1,3,5,7)$ ribbons obtained at a field of $1 \mathrm{kOe}$. (b) Corresponding $d M / d T(T)$ curves.

TABLE I

Nominal Composition, Curie Temperature of Magnetic Phase Transition $\left(\mathrm{T}_{\mathrm{C}}\right)$, MaXimal Magnetic EnTropy Changes, $\left(-\Delta \mathrm{S}_{\mathrm{M}}{ }^{\mathrm{max}}\right)$ and Relative Cooling Power (RCP) at Magnetic Field Change of 30 KOE OF $\mathrm{Fe}_{50-\mathrm{x}} \mathrm{Ni}_{\mathrm{x}} \mathrm{Mn}_{25} \mathrm{Ga}_{25}$ RIBBONS

\begin{tabular}{lllll}
\hline $\mathrm{X}$ & Nominal & $\mathrm{T}_{\mathrm{C}}$ & $-\Delta \mathrm{S}_{\mathrm{M}}{ }^{\mathrm{max}}$ & $\mathrm{RCP}$ \\
& composition & $(\mathrm{K})$ & $(\mathrm{Jkg} / \mathrm{K})$ & $(\mathrm{Jkg})$ \\
\hline 1 & $\mathrm{Fe}_{49} \mathrm{Ni}_{1} \mathrm{Mn}_{25} \mathrm{Ga}_{25}$ & 232 & 1.6 & 147.2 \\
3 & $\mathrm{Fe}_{47} \mathrm{Ni}_{3} \mathrm{Mn}_{25} \mathrm{Ga}_{25}$ & 242 & 1.4 & 126 \\
5 & $\mathrm{Fe}_{45} \mathrm{Ni}_{5} \mathrm{Mn}_{27} \mathrm{Ga}_{23}$ & 252 & 1.5 & 135 \\
7 & $\mathrm{Fe}_{43} \mathrm{Ni}_{7} \mathrm{Mn}_{27} \mathrm{Ga}_{23}$ & 257 & 1.5 & 130.5 \\
\hline
\end{tabular}

obtained for a field change of 30 kOe are shown in Fig. 4. The maximal magnetic entropy changes of $-\Delta S_{M}$, as a function of Ni content $\mathrm{x}$, are listed in Table I. The Ni substitution alters the magnetocaloric properties around the transition temperatures. The peak values of the maximal magnetic entropy changes, $-\Delta \mathrm{S}_{\mathrm{M}}{ }^{\max }$, are about 1.4-1.6 Jkg/K for Ni-substituted ribbons, at a maximum applied field of $30 \mathrm{kOe}$. The change in $-\Delta \mathrm{S}_{\mathrm{M}}$ should be caused by a change of magnetization around the transition temperatures. The difference in the magnetization can be ascribed to the exchange interaction on the magnetic moments of $\mathrm{Fe}$ and $\mathrm{Mn}$ atoms in $\mathrm{Ni}-\mathrm{Mn}$-based alloys. Hence, any change of the positions in $\mathrm{B} 2$ lattices caused by $\mathrm{Ni}$ addition could modify the strength of the interactions, leading to different magnetic exchanges in the phases, resulting in the change of magnetic entropy changes $-\Delta \mathrm{S}_{\mathrm{M}}$ and $\mathrm{T}_{\mathrm{C}}$.

Another important parameter for magnetic refrigeration is the refrigeration capacity $(\mathrm{RC})$, which is measured in literature by different methods [18]. The RC value represents how much heat can be transferred between cold and hot sinks in an ideal refrigerant cycle, [18] which is of practical significance. In present work, the $\mathrm{RC}$ values are estimated using the relative cooling power (RCP), which is given by the product of the $\Delta \mathrm{S}_{\mathrm{M}}(\mathrm{T})$ maximum $\left(\Delta \mathrm{S}_{\mathrm{M}}{ }^{\max }\right)$ and full width at half maximum of $\Delta \mathrm{S}_{\mathrm{M}}{ }^{\max }\left(\delta \mathrm{T}_{\mathrm{FWHM}}\right)$, i.e., $\mathrm{RCP}=-\Delta \mathrm{S}_{\mathrm{M}}{ }^{\max } \times \delta \mathrm{T}_{\mathrm{FWHM}}$. The RCP is approximately $4 / 3$ times larger than the cooling

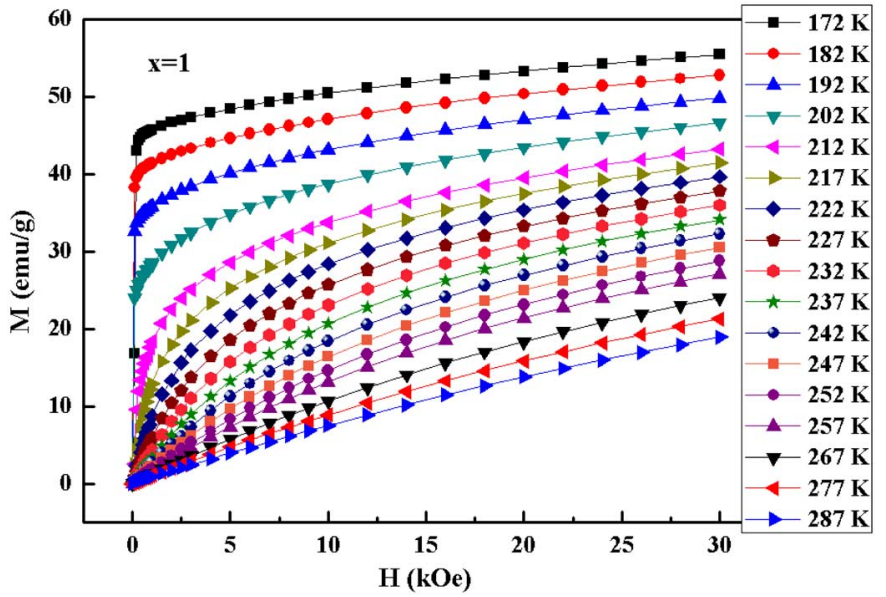

Fig. 4. Isothermal magnetization curves of $\mathrm{Fe}_{49} \mathrm{Ni}_{1} \mathrm{Mn}_{25} \mathrm{Ga}_{25}$ ribbons obtained for a field change of $30 \mathrm{kOe}$.

capacity for the same temperature interval. The RCP values for each of the $\Delta \mathrm{S}_{\mathrm{M}}$ peaks of $\mathrm{Fe}_{50-\mathrm{x}} \mathrm{Ni}_{\mathrm{x}} \mathrm{Mn}_{25} \mathrm{Ga}_{25}(\mathrm{x}=1-7)$ ribbons are also listed in Table I. The values of the RCP for $\mathrm{Fe}_{50-\mathrm{x}} \mathrm{Ni}_{\mathrm{x}} \mathrm{Mn}_{25} \mathrm{Ga}_{25}$ ( $\mathrm{x}=1-7$ ) ribbon samples are located in the range of 126-147.2 Jkg for a magnetic field change of $30 \mathrm{kOe}$, which is much larger than those of iron-based $\mathrm{Fe}_{60} \mathrm{Cr}_{14} \mathrm{Nb}_{3} \mathrm{Si}_{13} \mathrm{~B}_{9} \mathrm{Cu}_{1}$ alloy (87.3 Jkg) [19]. Therefore, despite relatively lower peak values of $-\Delta S_{M}$, but the relatively broader temperature range of the half maximum of $\Delta S_{M}$ peak ( $\sim 90 \mathrm{~K})$, low-cost, nontoxic elements and simple synthesis procedures still make $\mathrm{Fe}-\mathrm{Ni}-\mathrm{Mn}-\mathrm{Ga}$-based ribbons promising candidates for magnetic refrigeration applications close to room temperature.

\section{CONCLUSION}

The effect of Ni substitution for $\mathrm{Fe}$ in $\mathrm{Fe}_{50-\mathrm{x}} \mathrm{Ni}_{\mathrm{x}} \mathrm{Mn}_{25} \mathrm{Ga}_{25}$ $(\mathrm{x}=0-7)$ ribbons on the structure, magnetic phase transition and magnetocaloric properties has been reported. The experimental results show that the main phase of ribbons is changed with $\mathrm{Ni}$ concentration from the ordered fcc structure for $\mathrm{x}=0$ into $\mathrm{B} 2$-type structure for $\mathrm{x}=1-7$. A proper addition of $\mathrm{Ni}$ can improve the magnetic coupling between magnetic atoms, leading to enhanced both magnetization and Curie 
temperature. The maximum values of the magnetic entropy changes $-\Delta \mathrm{S}_{\mathrm{M}}{ }^{\max }$ are $1.6,1.4,1.5$ and $1.5 \mathrm{~J} / \mathrm{kg} \mathrm{K}$ at 232 , 242,252 and $257 \mathrm{~K}$ for $\mathrm{x}=1,3,5$, and 7, respectively, under applied magnetic field of $30 \mathrm{kOe}$. The moderate $\Delta \mathrm{S}_{\mathrm{M}}$ and RCP values and low cost elements suggest that $\mathrm{Fe}_{50-\mathrm{x}} \mathrm{Ni}_{\mathrm{x}} \mathrm{Mn}_{25} \mathrm{Ga}_{25}$ $(\mathrm{x}=1-7)$ ribbons may be promising substances for magnetic refrigeration materials working in the temperature interval range of $200-300 \mathrm{~K}$.

\section{ACKNOWLEDGMENT}

This paper was supported by National Science Council, Taiwan, under Grant NSC-101-2112-M-194-005-MY3.

\section{REFERENCES}

[1] K. Ullakko, J. K. Huang, C. Kantner, R. C. O'Handley, and V. V. Kokorin, "Large magnetic-field-induced strains in $\mathrm{Ni}_{2} \mathrm{MnGa}$ single crystals," Appl. Phys. Lett., vol. 69, no. 13, pp. 1966-1968, 1996.

[2] R. Kainuma, Y. Imano, W. Ito, Y. Sutou, H. Morito, S. Okamoto, O. Kitakami, K. Oikawa, A. Fujita, T. Kanomata, and K. Ishida, "Magnetic-field-induced shape recovery by reverse phase transformation," Nature, vol. 439, no. 7079, pp. 957-960, 2006.

[3] Z. D. Han, D. H. Wang, C. L. Zhang, H. C. Xuan, B. X. Gu, and Y. W. $\mathrm{Du}$, "Low-field inverse magnetocaloric effect in $\mathrm{Ni}_{50-\mathrm{x}} \mathrm{Mn}_{39+\mathrm{x}} \mathrm{Sn}_{11}$ Heusler alloys," Appl. Phys. Lett., vol. 90, no. 4, p. 042507, 2007.

[4] V. K. Sharma, M. K. Chattopadhyay, K. H. B. Shaeb, A. Chouhan, and S. B. Roy, "Large magnetoresistance in $\mathrm{Ni}_{50} \mathrm{Mn}_{34} \mathrm{In}_{16}$ alloy," Appl. Phys. Lett., vol. 89, no. 22, p. 222509, 2006.

[5] S. Y. Yu, Z. X. Cao, L. Ma, G. D. Liu, J. L. Chen, G. H. Wu, B. Zhang, and X. X. Zhang, "Realization of magnetic field-induced reversible martensitic transformation in NiCoMnGa alloys," Appl. Phys. Lett., vol. 91, no. 10, p. 102507, 2007.

[6] K. Koyama, H. Okada, K. Watanabe, T. Kanomata, R. Kainuma, W. Ito, K. Oikawa, and K. Ishida, "Observation of large magnetoresistance of magnetic Heusler alloy $\mathrm{Ni}_{50} \mathrm{Mn}_{36} \mathrm{Sn}_{14}$ in high magnetic fields," Appl. Phys. Lett., vol. 89, no. 18, pp. 182510-182513, 2006.
[7] M. Khan, I. Dubenko, S. Stadler, and N. Ali, "Exchange bias behavior in Ni-Mn-Sb heusler alloys," Appl. Phys. Lett., vol. 91, no. 7, p. $072510,2007$.

[8] M. Khan, I. Dubenko, S. Stadler, and N. Ali, "Exchange bias in bulk Mn rich Ni-Mn-Sn Heusler alloys," J. Appl. Phys., vol. 102, no. 11, p. $113914,2007$.

[9] W. Zhu, E. K. Liu, L. Feng, X. D. Tang, J. L. Chen, G. H. Wu, H. Y. Liu, F. B. Meng, and H. Z. Luo, "Magnetic-field-induced transformation in FeMnGa alloys," Appl. Phys. Lett., vol. 95, no. 22, p. 222512, 2009.

[10] X. D. Tang, W. H. Wang, W. Zhu, E. K. Liu, G. H. Wu, F. B. Meng, H. Y. Liu, and H. Z. Luo, "Giant exchange bias based on magnetic transition in gamma- $\mathrm{Fe}_{2} \mathrm{MnGa}$ melt-spun ribbons," Appl. Phys. Lett., vol. 97 , no. 24, p. 242513, 2010

[11] X. D. Tang, W. H. Wang, G. H. Wu, F. B. Meng, H. Y. Liu, and H. Z. Luo, "Tuning exchange bias by thermal fluctuation in $\mathrm{Fe}_{52} \mathrm{Mn}_{23} \mathrm{Ga}_{25}$ melt-spun ribbons," Appl. Phys. Lett., vol. 99, no. 22, p. 222506, 2011.

[12] C. W. Shih, X. G. Zhao, H. W. Chang, W. C. Chang, and Z. D. Zhang, "The phase evolution, magnetic and exchange bias properties in $\mathrm{Fe}_{50} \mathrm{Mn}_{24+\mathrm{x}} \mathrm{Ga}_{26-\mathrm{x}}(\mathrm{x}=0-3)$ melt-spun ribbons," J. Alloys Compounds, vol. 570, no. 0, pp. 14-18, 2013.

[13] K. A. Gschneidner and V. K. Pecharsky, "Magnetocaloric materials," Annu. Rev. Mater. Sci., vol. 30, no. 1, pp. 387-429, 2000.

[14] A. T. Zayak, P. Entel, K. M. Rabe, W. A. Adeagbo, and M. Acet, "Anomalous vibrational effects in nonmagnetic and magnetic heusler alloys," Physical Rev. B., vol. 72, no. 5, p. 054113, 2005.

[15] T. Gasi, A. K. Nayak, M. Nicklas, and C. Felser, "Structural and magnetic properties of the heusler compound $\mathrm{Fe}_{2} \mathrm{MnGa}$," J. Appl. Phys., vol. 113, no. 17, pp. 17E301-17E303, 2013.

[16] Y. V. Kudryavtsev, N. V. Uvarov, V. N. Iermolenko, I. N. Glavatskyy, and J. Dubowik, "Electronic structure, magnetic and optical properties of heusler alloy," Acta Materialia, vol. 60, no. 12, pp. 4780-4786, 2012.

[17] A. Inoue, "High strength bulk amorphous alloys with low critical cooling rates," Japan Inst. Metals, vol. 36, no. 7, pp. 866-875, 1995.

[18] K. A. Gschneidner, Jr., Jr., V. K. Pecharsky, A. O. Pecharsky, and C. B. Zimm et al., "Recent developments in magnetic refrigeration," Mater. Sci. Forum, vol. 315, p. 69, 1999.

[19] S. Atalay, H. Gencer, and V. S. Kolat, "Magnetic entropy change in $\mathrm{Fe}_{74-\mathrm{x}} \mathrm{Cr}_{\mathrm{x}} \mathrm{Cu}_{1} \mathrm{Nb}_{3} \mathrm{Si}_{13} \mathrm{~B}_{9}(\mathrm{x}=14$ and 17) amorphous alloys," $J$ Non-Crystalline Solids, vol. 351, no. 30-32, pp. 2373-2377, 2005 